\title{
Bradykinin-Induced Excitation of Afferent Cardiac Sympathetic Nerve Fibers
}

\author{
Yasumi Uchida, M.D. and Satoru Murao, M.D.
}

\begin{abstract}
SummaRY
The effect of bradykinin on afferent cardiac sympathetic nerve fibers has been examined. Using anesthetized dogs, the action potentials of the fibers were derived from either the 2 nd or 3 rd thoracic communicating ramus of the left side. Excitation of the afferent fibers was observed following administration of bradykinin acetate dissolved in physiological saline on the left ventricular wall. The minimum concentration required for excitation was $50-100 \mathrm{ng} / \mathrm{ml}$. The fibers were excited rhythmically synchronous with myocardial contraction and/or relaxation. However, no significant augmentation of myocardial contraction was produced by the agent. Bradykinin-induced excitation of the fibers was significantly reduced by pretreatment with acetylsalicylic acid. The results suggest bradykinininduced sensitization of the receptor sites of the afferent fibers for normal modality of left ventricular motion.
\end{abstract}

\section{Additional Indexing Words :}

Afferent sympathetic nerves Bradykinin acetate Acetylsalicylic acid Somato-autonomic reactions

\begin{abstract}
A number of humoral substances which may participate in cardiac pain $A$ induced by myocardial ischemia have been proffered, but without definite evidence. ${ }^{1)}$ Myocardial ischemia is accompanied by formation of bradykinin. ${ }^{2)}$ This substance is the most powerful of all the algesic agents. ${ }^{3}$ It causes pain in humans when it is applied to a blister base on the skin or when injected into somatic and visceral arteries ${ }^{4 /-7)}$ and elicites the pseudaffective response in animals when injected into the coronary artery. ${ }^{1)}$ However, it is unclear whether this agent activates the afferent cardiac sympathetic nerve fibers which subserve nociception of the heart. ${ }^{8)-10}$

Our studies have been undertaken to examine the effect of bradykinin acetate solutions on afferent sympathetic nerve fibers which originated in the left ventricular wall.
\end{abstract}

From the Second Department of Internal Medicine, Faculty of Medicine, University of Tokyo, Tokyo.

Received for publication September 12, 1973. 


\section{Methods}

Observations were carried out on adult mongrel dogs under intravenous pentobarbital sodium anesthesia, using a dose of $35-40 \mathrm{mg} / \mathrm{Kg}$. The trachea was intubated for artificial positive pressure respiration with air. The upper 8 ribs on the left side were removed. The left thoracic sympathetic trunk below the 4 th communicating ramus, the upper $4 \mathrm{rami}$ on the same side and the left cervical vagosympathetic trunk were transected. The 2 nd or $3 \mathrm{rd}$ ramus was dissected into fine filaments using a dissecting microscope at 10-20x magnification. One of the filaments was placed on bipolar electrodes connected to an a.c. coupled preamplifier. The electrodes and the nerve filament were covered with liquid paraffin.

The anterior aspect of the left heart was exposed by pericardiotomy. The left ventricular surface was tapped with the blunt tip of a bamboo bar $1 \mathrm{~mm}$ in diameter for determination of the receptive fields of the mechanosensitive fibers. The bamboo bar was connected to a strain gauge arch (Nihonkoden, Model 10). The pressure on the ventricular wall measured by the strain gauge arch was recorded on the running films simultaneously with the mechanically evoked action potentials. The conduction time from the receptive field to the recording electrodes was calculated from the time of the beginning of tapping to appearance of the action potential. The conduction time was used for the analysis of the relationship between cardiac motion and bradykinin-induced action potentials. A strain gauge arch was sewn on the anterior wall of the left ventricle for measurement of left ventricular motion. Left ventricular tension thus measured was expressed as grams force. The action potentials evoked by application of bradykinin solutions were recorded along with left ventricular tension. At the same time, the action potentials were employed to trigger a square-wave generator and the output was integrated by a pulse-integrator. The height of the integrated record indicated the number of the action potentials per second and was expressed as impulse/sec.

Bradykinin acetate was dissolved in physiological saline since physiological saline did not activate the afferent fibers. The concentrations of the solutions ranged from $1 \mathrm{ng}$ to $10 \mu \mathrm{g} / \mathrm{ml}$. A solution of $0.1 \mathrm{ml}$ was dripped to the receptive field and the another $0.1 \mathrm{ml}$ to the ventricular wall between the limbs of the strain gauge arch. The solutions were also dripped to the wall in the nerve preparations in which no response was produced by tapping.

The effect of $1 \mu \mathrm{g} / \mathrm{ml}$ bradykinin acetate was examined before and after administrations of $100-150 \mathrm{mg} / \mathrm{Kg}$ acetylsalicylic acid into the left jugular vein in 5 nerve preparations.

Three dogs were anesthetized with pentobarbital sodium in a dose of 25-30 mg/ $\mathrm{Kg}$. It was necessary to wait about 2 hours from anesthesia in order to obtain spontaneous respiration, tendon reflex, shudder and corneal reflex. The chest was opened by the method described above. The phrenic nerves and the cervical vago-sympathetic trunks were transected. Blood pressure was measured by a strain gauge connected to a catheter which was inserted into the right femoral artery. The movements of the right forelimb and the movements of the right thoracic wall which represented spontaneous respiration were monitored by strain gauge arches sewn on them. It was examined whether application of the solutions on the anterior wall of the left ventricle could elicite the somato-autonomic reactions which can be produced by coronary artery occlusion. ${ }^{10}$ 


\section{Results}

Tapping of the anterior wall of the left ventricle evoked action potentials in 13 nerve filaments in 10 dogs. A solution of $0.1 \mathrm{ml}$ bradykinin acetate, ranging from $1 \mathrm{ng}$ to $10 \mu \mathrm{g} / \mathrm{ml}$, was dripped to the receptive fields determined by tapping in these nerve preparations. Following application of the solutions, excitation was set up in all these nerves. The minimum concentration required for activation was $10-500 \mathrm{ng} / \mathrm{ml}$. The minimum concentration was little influenced by repeating application when the interval of application was over $5 \mathrm{~min}$. The latency for activation was $5.5-15 \mathrm{sec}$. The numbers of the action potentials increased gradually and it became the maximum in 10-30 sec after excitation began. All of the fibers fired irregularly for the initial several seconds and thereafter regularly with a close relation to each cardiac cycle (Fig. 1). The conduction time determined by topical tapping was $35-520 \mathrm{msec}$ in this study. Taking the conduction time into consideration, it was revealed that myocardial contraction was responsible for excitation in 3, relaxation in 2 and both con-

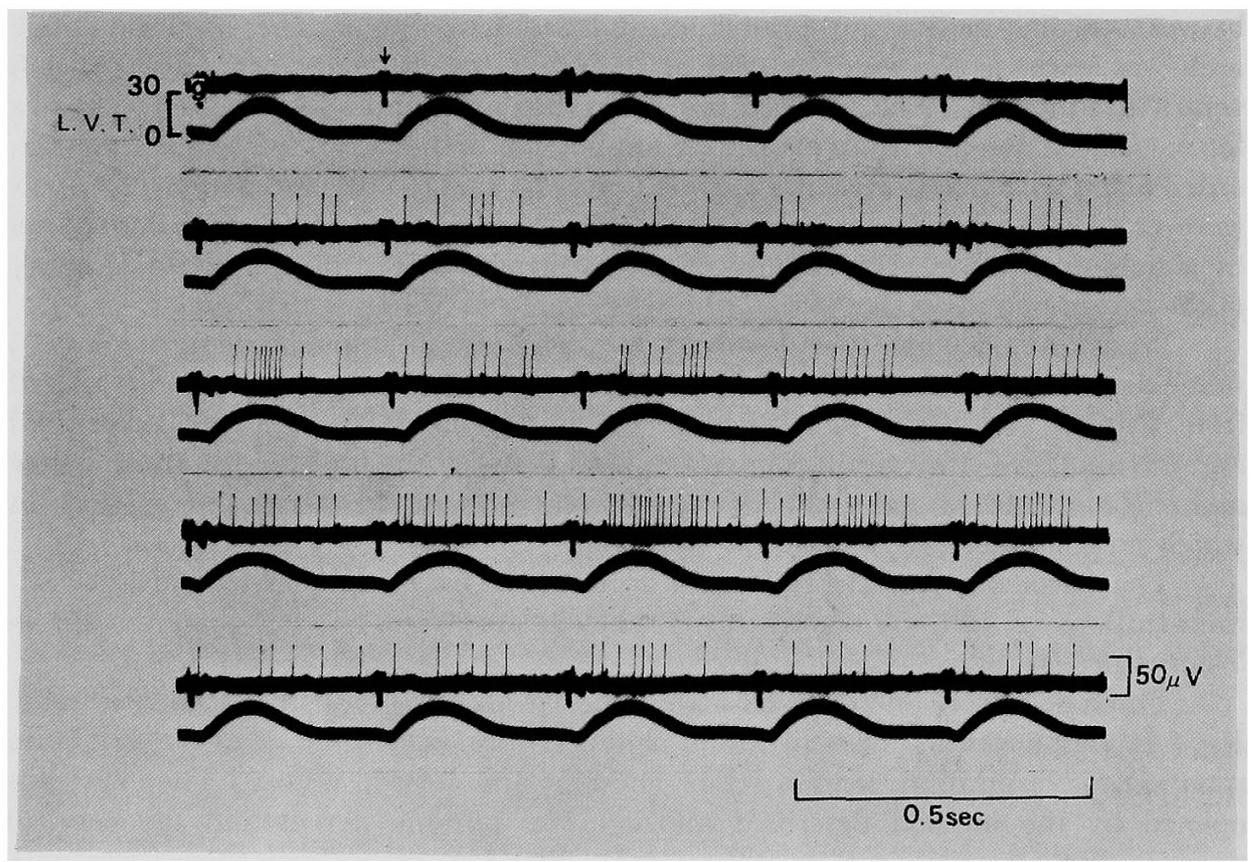

Fig. 1. Sequence of the afferent sympathetic action potentials evoked by bradykinin acetate. From the top: Control; 24, 35, 46, and $65 \mathrm{sec}$ after application of $500 \mathrm{ng} / \mathrm{ml}$ bradykinin acetate to the mechanically active portion of the left ventricular surface. Conduction time for the action potentials was $40 \mathrm{msec}$. L.V.T. = left ventricular tension. Upward motion of L.V.T. indicates myocardial contraction. The action potentials are contaminated by QRS of electrocardiogram (the downward arrow). 


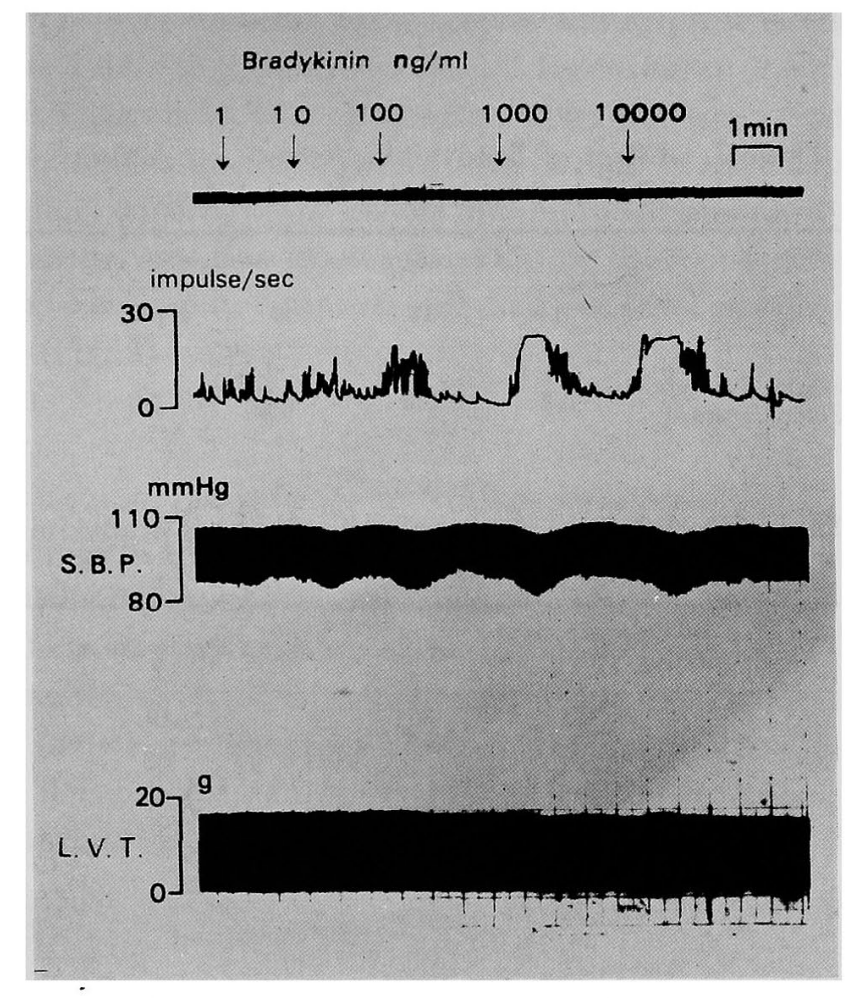

Fig. 2. Relationship between the number of the action potentials per second and concentrations of bradykinin acetate. From the top: Integrated action potentials, systemic blood pressure and left ventricular tension. Bradykinin acetate solutions were dripped to the left ventricular wall at downward arrows.

traction and relaxation for the remaining preparations. Application of the solutions of over $10 \mathrm{ng} / \mathrm{ml}$ also caused a slight fall in systemic blood pressure (Fig. 2). However, no significant change in left ventricular tension was produced by application of the solutions to the ventricular surface.

Application of the solutions was carried out in 28 nerve preparations in which tapping of the ventricular wall could not evoke the action potentials. Solutions of 100 and $500 \mathrm{ng} / \mathrm{ml}$ provoked the action potentials in 2 of these preparations. Although their conduction time was not measured, their rhythmical appearance had a close relation to each cardiac beat.

In 5 nerve preparations, the effect of pretreatment with acetylsalicylic acid on bradykinin-induced excitation was examined. A dose of 100-150 $\mathrm{mg} / \mathrm{Kg}$ was used since the pseudaffective response elicited by intra-coronary injections of bradykinin can be blocked by a dose of over $100 \mathrm{mg} / \mathrm{Kg} .^{1{ }^{1},{ }^{17} \text {, }}$ The maximum firing rate was reduced below 50 percent of the control value in 
all these preparations. The latency for the inhibitory effect was $10-15 \mathrm{~min}$ (Table II).

Table I. Effect of Bradykinin Acetate on Activity of Afferent Sympathetic Nerve Fibers

\begin{tabular}{l|cccccc}
\hline & \multicolumn{5}{|c}{ Concentrations of } & Bradykinin Acetate (ng/ml) \\
\cline { 2 - 6 } & 1 & 10 & 50 & 100 & 500 & 1,000 \\
\hline $\begin{array}{l}\text { Number of Fibers Excited/ } \\
\text { Number of Fibers Tested }\end{array}$ & $0 / 8$ & $2 / 8$ & $4 / 8$ & $5 / 9$ & $12 / 13$ & $13 / 13$
\end{tabular}

Table II. Effect of Acetylsalicylic Acid on BradykininInduced Excitation

\begin{tabular}{c|ccc}
\hline $\begin{array}{c}\text { Doses of Acetylsalicylic Acid } \\
(\mathrm{mg} / \mathrm{Kg})\end{array}$ & \multicolumn{3}{|c}{ Latency (min) } \\
\hline & 5 & 10 & 15 \\
100 & $0 / 3$ & $2 / 3$ & $3 / 3$ \\
150 & $0 / 2$ & $2 / 2$ & $2 / 2$
\end{tabular}

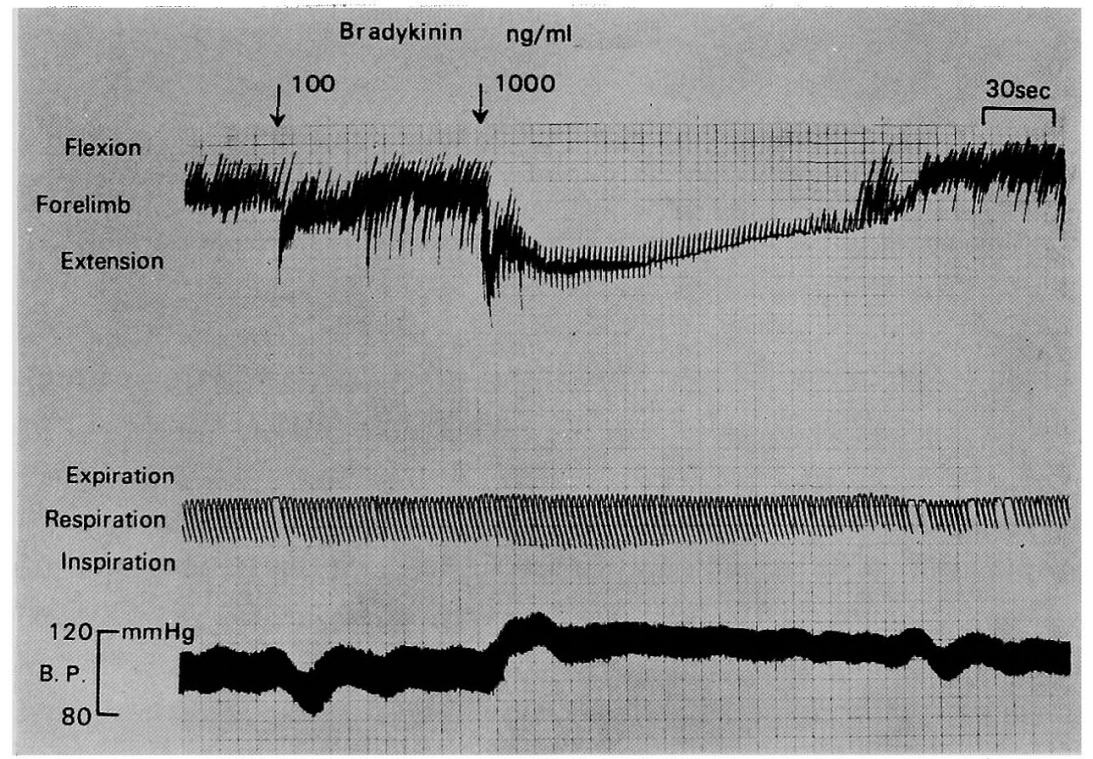

Fig. 3. Somato-autonomic reactions elicited by applications of bradykinin acetate solutions on the left ventricular wall. From the top: Motion of the right forelimb, spontaneous respiration and systemic blood pressure. High frequency component of the top record indicates shudder. Note, suppression of shudder, augmented spontaneous respiration, a rise in blood pressure and extension of the forelimb following application of $1,000 \mathrm{ng} / \mathrm{ml}$ bradykinin acetate. 
A solution of $1 \mu \mathrm{g} / \mathrm{ml}$ bradykinin acetate was dripped to the left ventricular surface in 3 lightly anesthetized dogs. Extension of the right forelimb and a transient suppression of spontaneous respiration were produced with a concentration of $100 \mathrm{ng} / \mathrm{ml}$. However, using a dose of over $500 \mathrm{ng} / \mathrm{ml}$, suppression of shudder superimposed on the forelimb extension and a rise in systemic blood pressure were provoked. In addition, the spontaneous respiration was augmented in its amplitude at first and then was reduced in both amplitude and frequency (Fig. 3).

\section{Discussion}

Nerve endings in the left ventricular wall that have their corresponding fibers in the cardiac sympathetic nerves have been demonstrated in man and animals. ${ }^{11)}$ Their afferent function as nociception of the heart has been demonstrated in animals. ${ }^{1), 8}$ The pain of angina pectoris can be eliminated by transection of the stellate ganglion through which the afferent nerve fibers pass. ${ }^{91}$ These nerve fibers can be excited by coronary constriction, ${ }^{10), 12), 13)}$ however, the mechanism for their excitation during coronary occlusion is unclear.

With respect to mechanosensitivity, there are a variety of afferent fibers from sensitive to resistant. ${ }^{10), 13), 14)}$ In this study, mechanosensitive fibers were mainly tested, since determination of the receptor site was necessary for topical application of bradykinin solutions. In addition, topical application is a more reasonable method than intra-coronary or systemic administrations, since the latters can activate the afferent fibers originating elsewhere than in the left ventricular wall. ${ }^{14)}$

Bradykinin is the strongest of the chemical agents in evoknig the pain in man. ${ }^{3-5)}$ This agent has been found to be far more potent in evoking the pseudaffective response when it is injected into the coronary artery than the other algesic agents." ${ }^{\prime \prime}$ Besides, this agent is formed during myocardial ischemia in the dog and during ischemia of the arm in man. ${ }^{2,15}$ Therefore, bradykinin has been proffered as a possible chemical mediator of ischemic pain." In this study, the afferent sympathetic nerve fibers were excited by application of bradykinin acetate solutions to the left ventricular wall. A concentration of $500 \mathrm{ng} / \mathrm{ml}$ was required for activation in the majority of the fibers, however, a small number were activated with a concentration of 10-50 $\mathrm{ng} / \mathrm{ml}$. Furukawa, et al noted that bradykinin in the coronary sinus blood increases up to $200 \mathrm{ng} / \mathrm{ml}$ during coronary artery ligation in the dog. ${ }^{2}$ This value is close to the minimum concentration required for activation of the majority of the fibers in this study. Concentration of bradykinin in the inter- 
stitial space and the occluded artery may be increased much more since the blood which drains from the ischemic wall into the coronary sinus may be diluted by the blood from the non-ischemic area. Therefore, there is a possibility that bradykinin participates in ischemia-induced excitation ${ }^{10}$ ) of the afferent cardiac sympathetic nerve fibers.

In this study, all of the fibers, irrespective of their response to topical mechanical stimuli, were activated by bradykinin. In addition, myocardial contraction and/or relaxation were found to be responsible for their activation. On the other hand, no significant augmentation of left ventricular contraction measured by a strain gauge arch was produced by the agent. Consequently, it is likely that bradykinin sensitized the nerve endings so that the normal intensities of myocardial motion excited the endings.

Antipyretic agents act as competitive antagonists and occupy the receptor sites. ${ }^{17)}$ The agents have been found to block the splenic nerves to bradykinin ${ }^{19}$ ) and the pseudaffective response elicited by intra-coronary injections of bradykinin. ${ }^{18)}$ In this study, acetylsalicylic acid suppressed excitation of the afferent fibers. The latency for its inhibitory effect was the same as that for blocking the bradykinin-induced pseudaffective response. ${ }^{18)}$

Following topical application of bradykinin, the somatic reactions such as extension of the limbs and disappearance of shudder occurred in addition to the changes in blood pressure and respiration. These reactions can be attributed to bradykinin-induced excitation of the afferent cardiac sympathetic nerves since the vagal afferent nerves had been transected.

Bradykinin administration produces cutaneous and vascular pain in man as well as the pseudaffective response in animals. With those results together with the observations made by Gutzman and Furukawa, it is interesting to speculate that kinins or bradykinin may participate in mechanism for production of anginal pain, in which excitation of the afferent cardiac sympathetic nerves is currently understood in relation to ischemia. However, definite evidence which supports this view still lacks.

\section{REFERENCES}

1. Guszman F, Lim RKS: Visceral pain and the pseudaffective response to intra-arterial injection of bradykinin and other algesic agents. Arch Int Pharmacodyn 136: 353, 1962

2. Furukawa $\mathbf{S}$, Hashimoto $\mathbf{K}$, Himura $\mathbf{E}$ et al: Changes in bradykininogen, bradykinin and bradykininase after experimental coronary ligation. Jap Circulat J: 33: 866, 1969

3. Keele CA, Armstrong O: Substances Producing Pain and Itch. Williams and Wilkins, Baltimore, 1964

4. Keele CA: Polypeptides Which Affect Smooth Muscle and Blood Vessels. M Schachter, Pergarnon Press, New York, 1960

5. Armstrong D, Dry HML, Keele CA: Observations on chemical excitants of cutaneous pain 
in man

6. Burch GE, Depasquale NP: Bradykinin, digital blood flow and the arteriorvenous anastomosis. Circulat Res 10: 105, 1962

7. Coffman JD: The effect of aspirin on pain and hand blood flow response in intra-arterial injection of bradykinin in man. Clin Pharmac Ther 7: 26, 1966

8. Sutton DC, Lueth HC: Experimental production of pain on excitation of the heart and great vessels. Arch Int Med 45: 827, 1930

9. White JC, Blard EF: The surgical relief of severe angina pectoris. Medicine 27: 1, 1948

10. Uchida Y, Kamisaka K, Ueda H: Anginal pain. Jap Circulat J 35: 147, 1971

11. Hirsch EF, Nigh CA, Kaye MF, Cooper T: Terminal innervation of the heart. Arch Path 77: 86,1964

12. Brown AM: Excitation of afferent cardiac sympathetic nerve fibers during myocardial ischemia. J Physiol 190: 35, 1967

13. Brown AM, Malliani A: Spinal reflexes initiated by coronary receptors. J Physiol 212: 685, 1971

14. Uchida $\mathrm{Y}$, Ueda $\mathrm{H}$ : Responses of cardiac sympathetic receptors to mechanically induced circulatory changes. Jap Heart J 10: 70, 1969

15. Uchida $\mathrm{Y}$, Ueda $\mathrm{H}$ : Kininogen and kinin activity during local ischemia in man. Jap Heart J 10: 503,1969

16. Uchida $Y$, Murao S: Effect of trasylol and acetylsalicylic acid on excitation of the afferent cardiac sympathetic nerve fibers during myocardial ischemia. Ann Meet Jap Soci Circulat 1973

17. Lim RKS, Gutzman F, Rodgers DW, Goto K, Braun G: Site of action of narcotic and nonnarcotic analgesics determined by blocking bradykinin evoked visceral pain. Arch Int Pharmacodyn 152: 25,1964

18. Gutzman F, Braun C, Lim RKS, Potter GD, Rodgers DW: Narcotic and non-narcotic analgesics which block visceral pain evoked by intra-arterial injection of bradykinin and other algesic agents. Arch Int Pharmacodyn 149: 571, 1964

19. Lim RKS: In 'Pain: Henry Ford Hospital International Symposium'. Little Brown, Boston, 1966 